\title{
Cryptogenic stroke as initial manifestation of CNS vasculitis: demonstration of vessel wall enhancement on 1.5T MRI using volumetric T1 TSE sequence
}

\author{
Khaled Badran, ${ }^{1}$ Avinash Kumar Kanodia, ${ }^{2}$ Mohamed Abdelsadg, ${ }^{1}$ James Galea
}

'Department of Neurosurgery, Ninewells Hospital, Dundee, UK ${ }^{2}$ Department of Radiology, Ninewells Hospital, Dundee, UK

Correspondence to Dr Avinash Kumar Kanodia, avinash.kanodia@nhs.net

Accepted 4 March 2018

\section{DESCRIPTION}

Central nervous system (CNS) vasculitis secondary to lupus anticoagulant is a rare but potentially lethal condition. ${ }^{1}$ We present a case report of a patient who presented with stroke and subsequently developed basilar artery ectasia and luminal abnormalities secondary to CNS vasculitis associated with antiphospholipid syndrome. We wish to highlight the role of relatively new MRI volumetric single slab 3D fast spin echo (FSE) sequence with slab-elective, variable excitation pulse, resulting in T1-weighting that does not cause vessel lumen enhancement although can show enhancement in inflamed vessel wall and other tissues.

A 56-year-old man initially presented with rightsided transient ischaemic attacks. He had a history of headaches and was thought to have aseptic meningitis in the past. Initial CT and MRI performed were normal. Within a few weeks, he re-presented with right hemiparesis and homonymous hemianopia. Imaging from his second admission demonstrated an acute infarct within the left posterior cerebral artery (PCA) territory (figure 1). MR angiogram showed a normal basilar top and occluded left PCA (figure 2). He improved clinically over the next few days although he was noted to have significant cognitive impairment which precluded his return to work. Ancillary investigations for stroke were in keeping with a diagnosis of antiphospholipid syndrome (high positive $\beta-2$ microglobulin antibodies) and a bubble echocardiogram also demonstrated a patent foramen ovale. He was therefore given anticoagulants. IgG and IgM anticardiolipin antibodies were normal. Antinuclear antibodies, antineutrophil cytoplasmic antibody and Extractable Nuclear Antigen (ENA) screen were negative. IgM anti- $\beta 2$ glycoprotein were within the normal range however anti- $\beta 2$ glycoprotein $\operatorname{IgG}$ were elevated, 89 (range 0-10). Lupus anticoagulation (Silica Clotting time) SCT ratio was 1.04 and the rest of thrombophilia screen was normal. $\operatorname{IgA}, \operatorname{IgG}$, and IgM were normal, but ACE was low, 8 (17-85). All coagulation profile, plasma viscosity, Liver Functions Tests (LFTs), U\&E and blood lipid and cholesterol were within normal range and no significant changes after repeating blood tests. CSF analysis could not be performed as the patient did not consent for it. He continued to have further episodes of intermittent headaches, right arm paraesthesia, facial numbness and dysphasia, from which he spontaneously recovered.

Six months later, he presented with acute exacerbation of headache, neck pain and stiffness. A CT head and CT angiogram demonstrated development of ectatic appearance of the basilar top with adjoining irregularity and luminal narrowing in basilar artery and PCAs (figure 3). Contrast-enhanced volumetric MRI using T1 sampling perfection with application optimised contrasts using different flip angle evolution (SPACE, Siemens Aera 1.5T) sequence showed diffuse circumferential enhancement of vessel wall of the basilar artery and PCAs, including focally ectatic basilar top and luminal irregularity, thereby confirming vessel wall inflammation (figure 4). The sequence parameters include TR $500 \mathrm{~ms}$, TE $7.2 \mathrm{~ms}$, voxel size $1 \times 1 \times 1 \mathrm{~mm}$, FoV 250 , base resolution 256 , slices per slab 208, acquisition time $6 \mathrm{~min}$. His overall clinical and imaging findings were discussed and consensus reached on CNS vasculitis, which
A) Check for updates

To cite: Badran K, Kanodia AK, Abdelsadg M, et al. BMJ Case Rep Published Online First: [please include Day Month Year]. doi:10.1136/bcr-2018 224352

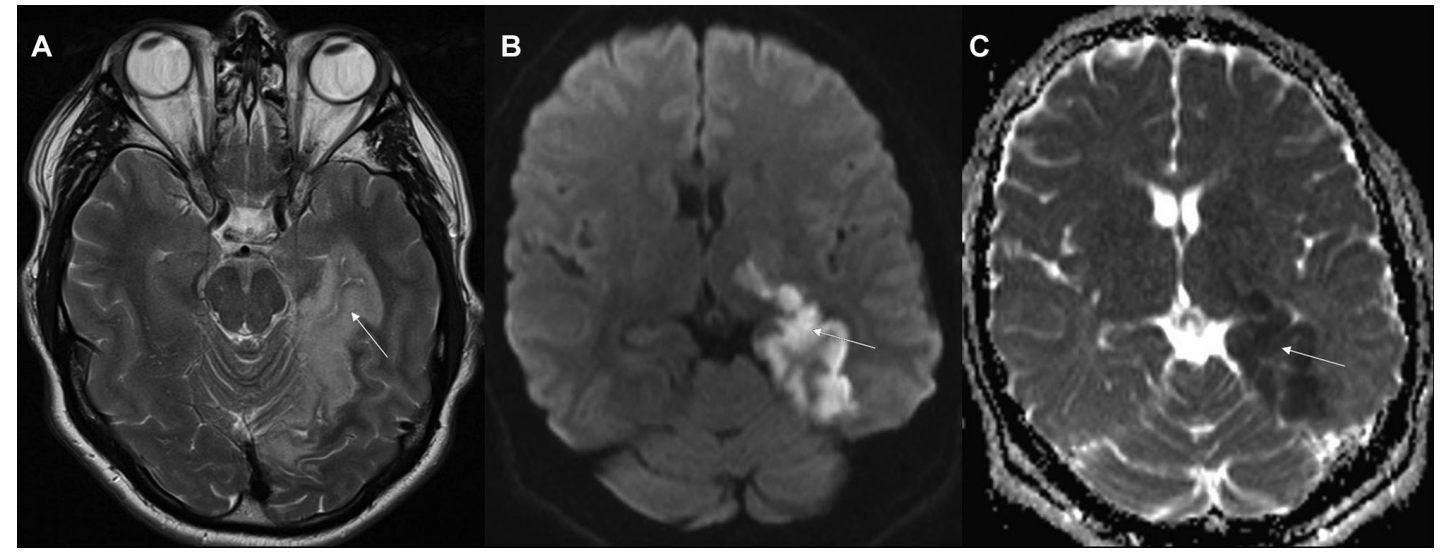

Figure 1 MRI. T2 axials (A), diffusion weighted images (B) and ADC map (C) showing acute left posterior cerebral artery territory infarct (white arrow). 


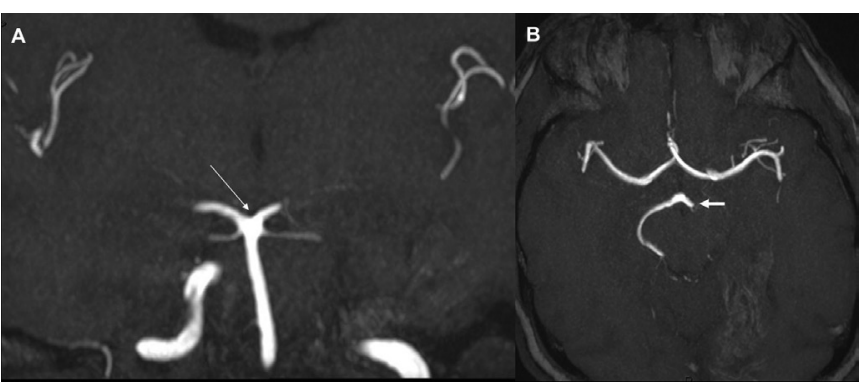

Figure 2 MR angiogram. Coronal (A) and axial (B) reconstructions using MIP. White arrow in (A) showing a normal looking basilar top. White arrow in (B) showing an occluded left posterior cerebral artery.

could also explain his old diagnosis of aseptic meningitis. He was given a course of methyprednisiolone tapering over 32 weeks and concomitantly given intravenous cyclophosphamide over the first 15 weeks with conversion to oral myciphenolate mofetil thereafter. He responded well clinically, and a further MR angiogram showed arrest of progression of his basilar ectasia although there was persistent enhancement of the vessel wall. There has been no further acute clinical deterioration in the last 6 months and he continues on follow-up.

CNS vasculitis is a difficult to diagnose entity and can result in stroke and vascular abnormalities including development of vascular ectasia, aneurysmal dilatation with potential haemorrhage. Vessel wall enhancement is a marker for vessel wall inflammation and an important feature in diagnosis particularly if it is significant and persistent, although it is non-specific for cause and sometimes may also be due to endothelial dysfunction. ${ }^{2}{ }^{3}$ It is important to select a sequence that causes vessel wall enhancement but not luminal enhancement. Typically, spin echo images are suitable for this purpose, since gradient echo images (GRE) cause luminal enhancement therefore wall and lumen cannot be separately identified on postcontrast images. It has traditionally been a technical challenge to use thin T1 spin echo images over a wide area. Different approaches have been used in the past, including using relatively thick $2 \mathrm{D}$ postcontrast images through areas of narrowing and using higher resolution sequences on 3T MRI. ${ }^{3-5}$ Using $2 \mathrm{D}$ technique has limitations that they may need cardiac gating, significantly increasing the acquisition time, plus the limited coverage, so need careful selection of the suspected area. It is technically difficult to demonstrate vessel wall enhancement on $1.5 \mathrm{~T}$ MRI with volumetric imaging, since most 3D T1 images on $1.5 \mathrm{~T}$ scanners are GRE type images. In this context, the newer volumetric T1 FSE sequence (SPACE sequence being an example) appears promising since it has spin echo type

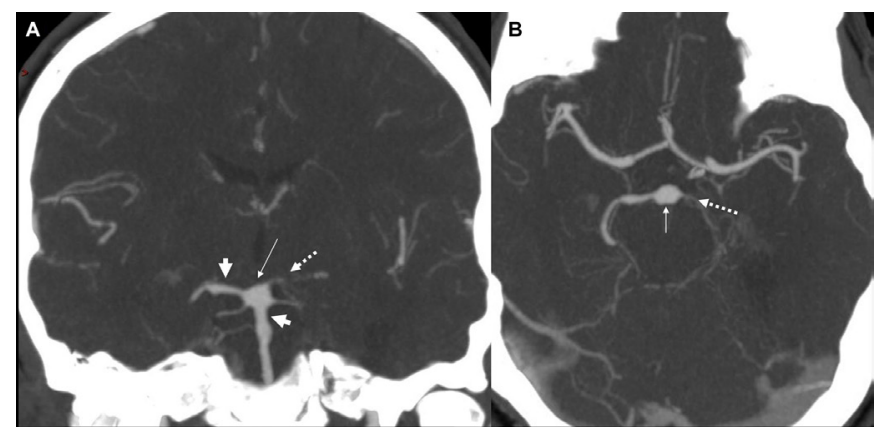

Figure 3 CT angiogram. Coronal (A) and axial (B) reconstructions using MIP. Basilar top is ectatic (thin white arrow in $A, B$ ). Associated luminal narrowing (short thick white arrows in $A$ ). Occluded left posterior cerebral artery (broken white arrow in $A, B$ ).

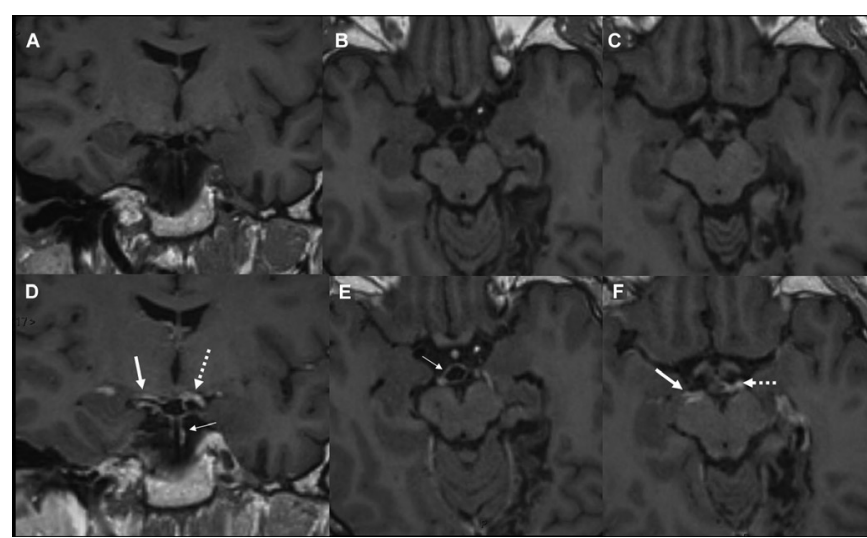

Figure 4 Volumetric T1 TSE sampling perfection with application optimised contrasts using different flip angle evolution (SPACE) sequence. Top row $(A-C)$ is non-contrast and bottom row (D-F) is postcontrast, corresponding postcontrast images are present below each precontrast image. Thin white arrow $(D, E)$ showing basilar artery wall enhancement. Thick white arrow $(D, F)$ showing right posterior cerebral artery (PCA) enhancement and broken white arrow (D,F) showing left PCA enhancement.

\section{Learning points}

- CNS vasculitis is a rare but devastating cause of neurological deficit and can be associated with ischaemic stroke and abnormalities of vessel wall and lumen.

- Vasculitis is difficult to prove on imaging.

- A newer MRI sequence on 1.5T, volumetric T1 TSE with variable flip angles, can be very useful to demonstrate vessel wall enhancement, indicating underlying vessel wall inflammation and should be routinely used in patients with suspected CNS vasculitis.

contrast. However, being a spin echo type sequence, it remains susceptible to flow related artefacts, including slow flow related and venous contamination. Correct diagnosis can result in early and optimum management that can halt the progression of disease and potentially prevent further complications. We believe that if available, T1 TSE volumetric sequence with contrast should be routinely used for patients with suspicion of vasculitis since demonstration of vessel wall enhancement can be helpful in making a correct diagnosis in these patients, which otherwise remains a difficult area to investigate, and the implications on treatment are significant since it often includes using steroids and immunosuppressants, while if untreated, the complications are potentially significant, including progressive vascular abnormalities and recurrent stroke.

Contributors All authors have contributed substantially to the manuscript. This includes planning, writing, formatting and approving the final manuscript. KB and AKK have provided the concept, KB, AKK, MA, JG have performed review of literature, AKK has provided images and legends and all authors have provided the content and approved it.

Funding This research received no specific grant from any funding agency in the public, commercial or not-for-profit sectors.

Competing interests None declared.

Patient consent Obtained.

Provenance and peer review Not commissioned; externally peer reviewed

(C) BMJ Publishing Group Ltd (unless otherwise stated in the text of the article) 2018. All rights reserved. No commercial use is permitted unless otherwise expressly granted. 


\section{REFERENCES}

1 de Amorim LC, Maia FM, Rodrigues CE. Stroke in systemic lupus erythematosus and antiphospholipid syndrome: risk factors, clinical manifestations, neuroimaging, and treatment. Lupus 2017;26:529-36.

2 Edjlali M, Gentric JC, Régent-Rodriguez C, et al. Does aneurysmal wall enhancement on vessel wall MRI help to distinguish stable from unstable intracranial aneurysms? Stroke 2014;45:3704-6.
3 Obusez EC, Hui F, Hajj-Ali RA, et al. High-resolution MRI vessel wall imaging: spatial and temporal patterns of reversible cerebral vasoconstriction syndrome and central nervous system vasculitis. AJNR Am J Neuroradiol 2014;35:1527-32.

4 Küker W. Imaging of cerebral vasculitis. Int J Stroke 2007;2:184-90.

5 Kontzialis M, Wasserman BA. Intracranial vessel wall imaging: current applications and clinical implications. Neurovasc Imaging 2016;2:4.

Copyright 2018 BMJ Publishing Group. All rights reserved. For permission to reuse any of this content visit

http://group.bmj.com/group/rights-licensing/permissions.

BMJ Case Report Fellows may re-use this article for personal use and teaching without any further permission.

Become a Fellow of BMJ Case Reports today and you can:

- Submit as many cases as you like

- Enjoy fast sympathetic peer review and rapid publication of accepted articles

- Access all the published articles

- Re-use any of the published material for personal use and teaching without further permission

For information on Institutional Fellowships contact consortiasales@bmjgroup.com

Visit casereports.bmj.com for more articles like this and to become a Fellow 